\title{
Caring for a child with Cerebral Palsy: The experience of Zimbabwean mothers
}

\author{
Authors: \\ Jermaine M. Dambi ${ }^{1}$ \\ Jennifer Jelsma² \\ Tecla Mlambo ${ }^{1}$ \\ Affiliations: \\ ${ }^{1}$ Department of \\ Rehabilitation, University \\ of Zimbabwe, Zimbabwe \\ ${ }^{2}$ Department of Health and \\ Rehabilitation Sciences, \\ University of Cape Town, \\ South Africa

\section{Correspondence to:} \\ Jermaine Dambi \\ Email: \\ jermainedambi@gmail.com \\ Postal address: \\ AV 178 Avondale Harare, \\ Zimbabwe \\ Dates: \\ Received: 28 Oct. 2014 \\ Accepted: 15 Jun. 2015 \\ Published: 13 Aug. 2015 \\ How to cite this article: \\ Dambi, J.M., Jelsma, J. \& \\ Mlambo, T. 2015, 'Caring \\ for a child with Cerebral \\ Palsy: The experience of \\ Zimbabwean mothers', \\ African Journal of Disability \\ 4(1), Art. \#168, 10 pages. \\ http://dx.doi.org/10.4102/ \\ ajod.v4i1.168

\section{Copyright:} \\ C 2015. The Authors \\ Licensee: AOSIS \\ OpenJournals. This work is \\ licensed under the Creative \\ Commons Attribution \\ License.
}

\section{Read online:}

Background: The needs of caregivers of children with disability may not be recognized despite evidence to suggest that they experience increased strain because of their care-giving role. This strain may be exacerbated if they live in under-resourced areas.

Objectives: We set out to establish the well-being of caregivers of children with Cerebral Palsy (CP) living in high-density areas of Harare, Zimbabwe. In addition, we wished to identify factors that might be predictive of caregivers' well-being. Finally, we examined the psychometric properties of the Caregiver Strain Index (CSI) within the context of the study.

Method: Caregivers of 46 children with CP were assessed twice, at baseline, and after three months, for perceived burden of care and health-related quality of life (HRQoL) using CSI and EQ-5D respectively. The psychometric properties of the CSI were assessed post hoc.

Results: The caregivers reported considerable caregiver burden with half of the caregivers reporting CSI scores in the 'clinical distress' range. Many of the caregivers experienced some form of pain, depression and expressed that they were overwhelmed by the care-giving role. No variable was found to be associated with clinical distress. The CSI demonstrated good overall internal consistency (Cronbach's Alpha $=0.8)$, stability over time $(Z=0.87, p=0.381)$ and was significantly and negatively correlated with the EQ-5D VAS (Spearman's rho $=-0.33$, $p=0.027$ ), demonstrating concurrent validity.

Conclusion: Caregivers must be monitored routinely for their level of distress and there is an urgent need to provide them with support. The CSI is likely to be a valid measure of distress in this population.

\section{Introduction}

\section{Problem statement}

Cerebral Palsy $(\mathrm{CP})$ is the most common physically disabling paediatric condition globally (Gagliardi et al. 2008). The prevalence in Zimbabwe is estimated to be at 1.55 per 1000 in rural areas and 3.3 per 1000 in urban areas (Finkenflugel et al. 1996). It is characterised by multiple impairments and functional limitations; essentially, it is a group of disorders that affects the development of movement and posture (Aisen et al. 2011). In Harare, the capital city of Zimbabwe, there are very few opportunities to place young children in appropriate day-care facilities, particularly those with severe disabilities from families with limited financial resources. Rehabilitation is provided on an intermittent basis by state institutions but caregivers, mostly mothers and sometimes members of the extended family do the dayto-day care.

Even in contexts in which there may be more supportive care available, caring for a child with physical disabilities may have a negative impact on the health and well-being of caregivers (Moster et al.2010; Raina et al. 2005). CP is associated with multiple impairments and consequently, it is associated with multiple activity limitations and participation restrictions (Deepthi \& Krishnamurthy 2011; Martin et al. 2005; Moster et al. 2010; Sharan et al. 2012).

Although the child with a disability may be a source of joy to the parents, their special needs may add to the emotional, physical and financial strain inherent in raising children, particularly in under-resourced settings. In addition, there is a consensus that long-term care-giving may affect physical, social and emotional health of the caregivers, their well-being, marital relationships, and employment and financial status (Davis et al. 2009; Yilmaz, Erkin \& Ezke 2013). These added concerns may lead to subsequent deterioration of health and health-related quality of life of the caregivers (HRQoL) (Berker \& Yalçin 2008; Deepthi \& Krishnamurthy 2011; Jones et al. 2007; Martin et al. 2005; Oh \& Lee 2009; O'Shea 2008; Rodrigues dos Santos et al. 2009). It is obviously also in the best interest of the child that strain in their caregivers be recognized and appropriate 
support given. Caregiver strain is defined as 'strain or load borne by a person who cares for a family member with a disability' (Oh \& Lee 2009).

\section{Background}

Although there have been several studies on the strain experienced by caregivers of children with CP (Davis et al. 2009; Palamaro Munsell et al. 2012), little is known regarding the situation of mothers and other caregivers within a situation of extreme resource limitation, such as exists within the high-density (township) areas of Harare. In general, there is little information on the HRQoL of caregivers of children with CP in low income countries as most of the available information originates in high-income countries. In addition, HRQoL is context-specific and culturally dependent (Bakas et al. 2012; Cieza \& Stucki 2005). We did not know what the level of strain on caregivers of children with $\mathrm{CP}$ was and we do not know what factors exacerbate the strain.

We identified likely contributors to increased strain as those being related to the condition of the child and those related to the caregiver. We hypothesised that strain would be increased if the physical demands of caring were increased. In other words, caring for older children and more disabled children might result in greater strain. Further, although CP is a non-progressive condition, the impact of the functional limitations becomes more apparent as the child ages. As the child increases in body size and weight, the need for greater and more complex mobility increases, making functional impairment more apparent and severe. Further, the clinical manifestations of $\mathrm{CP}$ evolve with time and impairments such as spasticity may increase and lead to more severe functional limitations (Karande, Patil \& Kulkarni 2008; Martin et al. 2005). Depending on the level of severity and type of $\mathrm{CP}$, some children may be dependent on caregivers with assistance in activities of daily living (ADLs) (Murphy et al. 2007; Sawyer et al. 2011; Tadema, Vlaskamp \& Needs 2009). This may well take a physical toll on the caregivers as the child becomes older and heavier. In addition, CP is a lifetime condition; it therefore requires a lifetime commitment from the caregiver (Berker \& Yalçin 2008; Jones et al. 2007), particularly when there are no respite facilities available.

In addition, a poor health-related quality of life might also be associated with greater strain in caregivers. This would be consistent with literature which states that caregiving can lead to physical strain that negatively affects the caregivers' physical HRQoL (Brehaut et al. 2004; Eker \& Tüzün 2004; Jelsma et al. 2001; Navaie-Waliser et al. 2002). Those who report problems with their own mobility or who are experiencing pain or anxiety and/or depression might also report more strain on the CSI. Older caregivers might be likely to experience more difficulty in physically caring for the child. In Zimbabwe, the impact of HIV might result in grandparents or other relatives taking responsibility for caring for the child if the biological mother is ill or has passed away. It is unclear whether the relationship of the child to the caregiver would either increase or decrease strain.

Finally, we wished to explore the impact of socioeconomic and demographic conditions on reported strain. Studies consistently report that care-giving can result in an increased financial burden (Brehaut et al. 2004; Centre 2010; Davis et al. 2009; Murphy et al. 2007; Navaie-Waliser et al. 2002; O'Shea 2008; Raina et al. 2004; Rodrigues dos Santos et al. 2009). We expected that those who were experiencing financial hardship and were unemployed were more likely to report higher levels of strain.

In order to ensure the internal validity of the study, it was necessary to validate the Caregiver Strain Index (CSI) as it has not been used within the Zimbabwean context before to the best of our knowledge. The CSI is a generic tool for assessing the burden of caregiving on the well-being of informal caregivers (Sullivan 2002). A review of the literature revealed that there are more than 74 tools measuring the burden of care, and these tools have been used in different settings (Whalen \& Buchholz 2009). Of these, the CSI was deemed an appropriate tool as it captures the multidimensionality of the burden of care, has demonstrated sound psychometric properties, it is short and easy to administer, and has been used previously in caregivers of children with CP (Narekuli, Raja \& Kumaran 2011; Robinson 1983; Sullivan 2002).

\section{Objectives}

The objectives of the study were therefore to establish what proportion of caregivers of children with Cerebral Palsy (CP) living in high-density areas of Harare, Zimbabwe, reported excessive strain. In addition, we wished to identify factors, such as severity of the functional limitation of the child, age of child or caregiver and demographic variables that might be predictive of their strain levels. Finally, we wished to examine the psychometric properties of the Caregiver Strain Index (CSI) within the context of the study.

\section{Contribution to the field}

The study aimed to provide information related to the caregivers of children with $\mathrm{CP}$ in a very under-resourced area. The context is different to those in the published literature as there are few public support systems in place and the caregivers are likely to bear the burden and benefits of caring for a child with disabilities with little assistance. Through identifying the degree of caregiver strain and exploring which factors are related to this strain, rehabilitation workers and others may be able to use the scarce resources available to assist those caregivers who are most likely to need support by providing them with targeted support.

\section{Research method and design Research setting}

The study participants were recruited from two of the central hospitals in Harare, Zimbabwe. One of the 
centres, Chitungwiza Central hospital $(\mathrm{CCH})$, is located in Chitungwiza, a satellite town located 30 kilometres away from Harare. Children with $\mathrm{CP}$ receive physiotherapy services as outpatients at this centre. The other participants were recruited from Harare Central Hospital $(\mathrm{HCH}) . \mathrm{HCH}$ is one of the largest referral centres in Zimbabwe and children with $\mathrm{CP}$ receive services from Children's Rehabilitation Unit (CRU), both as outpatients or under the outreach programme. The CRU conducts outreach services in 14 highdensity suburbs in Harare periurban area. Respondents from the $\mathrm{HCH}$ were recruited from the Mabvuku outreach point. Mabvuku is a high-density suburb of Harare that is located 17 kilometres east of the city centre. The children and caregivers (mostly mothers) in the outreach group (OR) gathered twice a month at a community centre. The respondents from $\mathrm{CCH}$ formed the hospital-based group and were recruited during their outpatient appointments. The frequency of appointments for this group was variable and dependent on the discretion of the treating therapists. In both arms, children received individual face-to-face treatment from therapists. In addition, the OR arm received group activities, where caregivers were requested to demonstrate home exercise programmes to other caregivers as well as sharing the challenges and achievements of caregiving.

\section{Study design and participants}

A descriptive and analytical longitudinal design was used.

A sample of convenience was drawn from the children treated at $\mathrm{CCH}^{\prime}$ s outpatients department and Mabvuku outreach point. We recruited 46 informal (unpaid) caregivers of children with $\mathrm{CP}$ with 20 being recruited from the OR group and 26 from the IB group. They were the primary caregivers, that is, those who were responsible for the daily care of the children. The children had to have a diagnosis of $\mathrm{CP}$ according to their doctors' notes. Only children up to 12 years of age were recruited as the discharge age for the CRU Outreach Programme is 12 years. Further, children who had comorbidities (such as spinal bifida) were excluded.

Assuming mean CSI scores of seven and nine $(\mathrm{SD}=2)$ between the two groups (Narekuli et al. 2011), the expected minimal number of cases was 32 to detect a significant change with $80 \%$ power over time.

\section{Instruments}

The socio-demographical details were captured through a researcher designed demographics questionnaire. The clinical details for children with $\mathrm{CP}$ were extracted from the patient notes. In addition, two instruments were used to assess the impact of caring for a child with CP. These were the CSI that measures caregiver burden of care and the EQ$5 \mathrm{D}$ that assesses HRQoL of the caregiver. In addition, the Gross Motor Function Classification System (GMFCS) was used to assess the severity of the child's condition. As the level of literacy and English proficiency is high in Harare, the CSI was not translated into the vernacular, Shona.

\section{The Caregiver Strain Index}

The Caregiver Strain Index (CSI) is a validated and reliable tool (alpha $=0.86$ ) for measuring the multidimensionality of burden of care-giving (Chen \& Hu 2002). The respondents are required to respond with a 'yes' or a 'no' over 13 statements. Statements such as 'it is a physical strain', 'there have been family adjustments' and 'it is a financial strain' exemplify items that assess the physical, psychosocial and economic domains of the burden of care respectively (Chen \& Hu 2002; Robinson 1983). A 'yes' is given a score of one, and a 'no' is given a score of zero. Summation of 'yes' responses give the total score that ranges from 0 to 13 . A score of seven or more signifies a high level of stress (Robinson 1983).

Although originally developed to measure the burden of caregiving the elderly with chronic illness (Robinson 1983), the CSI has been used in evaluating the impact of caregiving adults with stroke (Bugge, Alexander \& Hagen 1999; Post et al. 2007), cancer (Chen \& Hu 2002), multiple sclerosis (Khan, Pallant \& Brand 2007), amongst others. It had not been previously validated in the Zimbabwean population.

\section{The EuroQol 5 dimensions questionnaire}

The EuroQol 5 dimensions questionnaire (EQ-5D) is a generic, standardised and validated tool to assess HRQoL in adults (Cheung et al. 2011). In the first section of the tool, respondents rate their own health in five domains on a three-point Likert scale. The domains include mobility, self-care, usual activities, pain or discomfort and anxiety or depression. Respondents can rate if they have 'no problem', a 'moderate problem' or an 'extreme problem', and they are rated as one, two or three respectively (Cheung et al. 2011). Utility scores are then used to transform the five-digit number obtained from scoring the five dimensions into a discrete figure (Cheung et al. 2011). Utility scores for the Zimbabwean population are available (Jelsma et al. 2001). The second section of the tool is the EQ$5 \mathrm{D}$ visual analogue scale; respondents rate their health by marking on a linear scale which ranges from 0-100. The tool has been translated into several languages including Shona, a Zimbabwean native language. The Shona version of the EQ-5D has demonstrated good psychometric properties, that is, it is valid and has high test-retest reliability in measuring HRQoL in the Zimbabwean adult population (Jelsma et al. 2001).

\section{The Gross Motor Function Classification System}

Functional prognosis of $\mathrm{CP}$ is dependent on level of severity and this we measured using the Gross Motor Function Classification System (GMFCS), which is a valid and reliable tool (Debuse \& Brace 2011; Gorter et al. 2004). This classifies severity on a five-level ordinal scale, with children in level one being least affected and level five being more severely affected and functionally dependent (Gorter et al. 2004).

\section{Procedure \\ Ethical considerations}

Ethical approval was granted by the University of Cape Town (ref. 109/2012) and the Medical Research Council of 
Zimbabwe (MRCZ/B/333). Informed written consent was sought from the caregivers and rehabilitation professionals. Verbal assent was requested from children who could communicate $(n=5)$. Caregivers were assigned identity numbers to preserve confidentiality and only the principal researcher had access to the collected raw data, which was kept in a safe locker.

The research team recruited caregivers over four consecutive weeks. Caregivers were approached as they were awaiting services or after their children were treated. Once informed consent had been obtained, CSI and EQ-5D questionnaires were distributed to caregivers and were self-administered. The principal researcher then assessed and documented the severity of children with $\mathrm{CP}$ using the GMFCS. The participants were provided with snacks and drinks after data collection procedures.

\section{Analyses}

Descriptive statistics were used to describe the sample demographics as well as the frequencies of reported problems on the EQ-5D and CSI. The Chi-squared and sign tests were used to compare the differences in range of CSI scores, the most reported problems on the CSI and health profiles of caregivers on the domains of the EQ-5D over the three months of the study. The $t$-test was used to compare EQ-5D utility and VAS scores at baseline and after three months.

\section{Results}

\section{Demographic characteristics of the sample}

Table 1 shows the general demographic characteristics of the sample.

\begin{tabular}{|c|c|c|}
\hline Variable & Attribute & $f(\%)$ \\
\hline \multirow[t]{2}{*}{ Sex of children with Cerebral Palsy } & Males & $25(54)$ \\
\hline & Females & $21(46)$ \\
\hline $\begin{array}{l}\text { Mean age of children in months } \\
\text { (Standard Deviation)* }\end{array}$ & & $26(36)^{*}$ \\
\hline \multirow[t]{5}{*}{ GMFCS Level } & 1 (least affected) & $13(28.3)$ \\
\hline & 2 & $7(15.2)$ \\
\hline & 3 & $6(13)$ \\
\hline & 4 & $4(8.7)$ \\
\hline & 5 (most affected) & $16(34.8)$ \\
\hline \multirow[t]{4}{*}{ Cerebral Palsy type } & Spastic & $37(80.4)$ \\
\hline & Athetoid or dyskinetic & 5 (10.9) \\
\hline & Ataxic & $2(4.3)$ \\
\hline & Mixed & $2(4.3)$ \\
\hline $\begin{array}{l}\text { Mean caregiver age (Standard } \\
\text { Deviation)* in years }\end{array}$ & & $30.4(9.2)$ \\
\hline \multirow[t]{3}{*}{ Relationship to child } & Mother & $38(82.6)$ \\
\hline & Grandmother & 5 (10.9) \\
\hline & Sibling & $3(6.5)$ \\
\hline \multirow[t]{4}{*}{ Caregiver educational level } & Primary & $4(8.7)$ \\
\hline & Secondary & $30(65.2)$ \\
\hline & Tertiary & $9(19.6)$ \\
\hline & None & $3(6.5)$ \\
\hline \multirow[t]{3}{*}{ Caregiver employment status } & Unemployed & $28(60.9)$ \\
\hline & Informally employed & $14(30.4)$ \\
\hline & Formally employed & $4(8.7)$ \\
\hline
\end{tabular}

The mean age of the children was $26(\mathrm{SD}=36)$ months with males constituting the majority $(n=25,54 \%)$. Spastic CP was the predominant subtype ( $n=37$, $80.4 \%$ ). Each level of GMFCS ability was represented with approximately one third in the least $(28 \%)$ and one third in the most severely affected levels $(35 \%)$. The caregivers were predominantly mothers $(n=38,82.6 \%)$ and their mean age was $30.4(\mathrm{SD}=9.2)$ years. Most of the caregivers had secondary education $(84.8 \%)$ and were unemployed (60.9\%).

\section{Caregiver strain as measured by the Caregiver Strain Index scores}

More than half of the caregivers reported experiencing inconvenience, physical strain, confinement, family adjustments, disrupted personal plans, work adjustments, financial strain and being overwhelmed at baseline. The proportions remained greater than $50 \%$ at three months except for family adjustments and confinement, which decreased to below $50 \%$ (Table 2). At both times, the greatest number reported problems with financial strain and feeling overwhelmed. There were no significant differences in the proportions of positive responses to any category over the three months of the study.

Further, the majority of caregivers experienced a high burden of care (Table 2$)$ as $50 \%(n=23)$ of the caregivers had scores greater than or equal to seven which is the cut-off point for caregiver stress (or strain). The sign test indicated that there were no statistically significant changes in CSI scores over three months $(p=1.0)$. There were also no significant differences in the median scores between the two groups or in the proportion reporting clinical distress (score greater than seven) either at baseline $(p=0.385)$ or three months $(p=0.221)$, although two caregivers had developed clinical distress during this time.

\section{Health-related quality of life (HRQoL) of care givers}

Most of the caregivers reported that they had no problems with mobility, self-care, and usual activities, whereas many reported some or pain or discomfort and anxiety or depression, with the passage of time (Table 3).

\section{Factors associated with caregivers' strain}

Our findings (see Table 4) revealed that there was no association between clinical stress and the following variables:

- the child's age

- the severity of $\mathrm{CP}$

- caregivers' age

- caregivers' relationship with child

- caregivers' educational status.

The only association that approached significance was between clinical stress and unemployment in that there were 
TABLE 2: Proportion of caregivers reporting caregiver strain $(n=46)$.

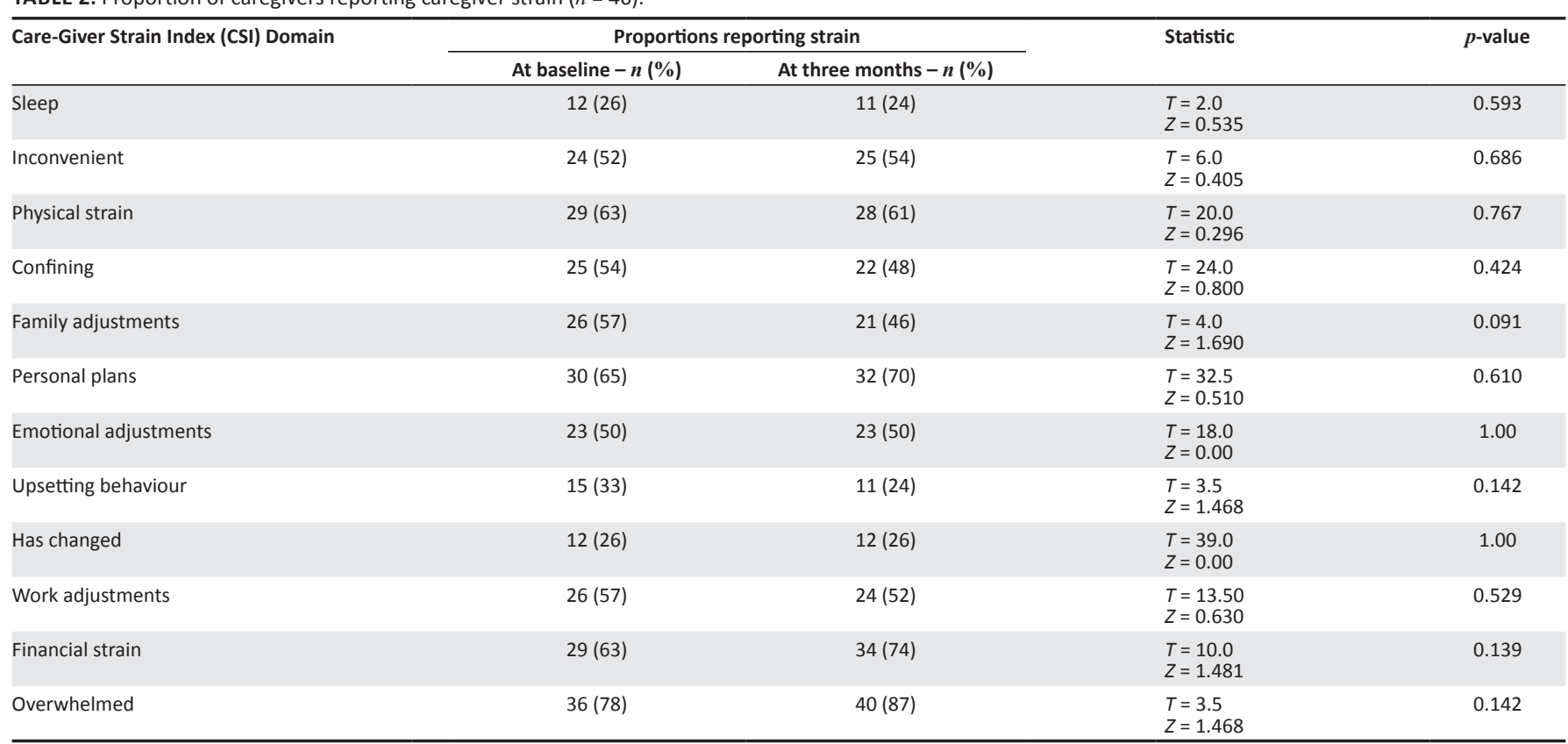

TABLE 3: Comparison of EQ-5D results from the present study and the EQ-5D Shona version validation study.

\begin{tabular}{|c|c|c|c|c|c|}
\hline EQ-5D domain & Response & $\begin{array}{c}\text { Present study }-N=46 \\
n(\%)\end{array}$ & $\begin{array}{c}\text { EQ-5D validation study }-N=38 \\
n(\%)\end{array}$ & Statistic & $p$-value \\
\hline \multirow[t]{2}{*}{ Mobility } & No problems & $31(67.4)$ & $33(86.8)$ & $\chi^{2}=10.192 \alpha$ & 0.001 \\
\hline & Some problems & $15(32.6)$ & $5(13.2)$ & $d f=1$ & \\
\hline \multirow[t]{2}{*}{ Self-care } & No problems & $38(82.6)$ & $37(97.4)$ & $\chi^{2}=10.889 \alpha$ & 0.002 \\
\hline & Some problems & $8(17.3)$ & $1(2.6)$ & $d f=1$ & \\
\hline \multirow[t]{2}{*}{ Usual activities } & No problems & $31(67.4)$ & $32(84.2)$ & $\chi^{2}=6.919 \alpha$ & 0.009 \\
\hline & Some problems & $15(32.6)$ & $6(15.8)$ & $d f=1$ & \\
\hline \multirow[t]{2}{*}{ Pain or discomfort } & No problems & $14(30.4)$ & $20(52.6)$ & $\chi^{2}=9.968 \alpha$ & 0.002 \\
\hline & Some problems & $32(69.6)$ & $18(47.4)$ & $d f=1$ & \\
\hline \multirow[t]{2}{*}{ Anxiety or depression } & No problems & 9 (19.6) & $18(47.4)$ & $\chi^{2}=15.172$ & 0.000 \\
\hline & Some problems & $37(80.4)$ & $20(52.6)$ & $d f=1$ & - \\
\hline
\end{tabular}

$\alpha$; with Yates correction of continuity

$\chi^{2}$, chi-square; $d f$, degrees of freedom

TABLE 4: Relationship between caregivers who were strained and age of children, severity of Cerebral Palsy (CP), caregivers' age, caregiver relational status, caregivers' educational and employment status.

\begin{tabular}{|c|c|c|}
\hline Variable & Statistic & $p$-value \\
\hline Age of children with CP (months) & $\begin{array}{l}U=263.5 \\
Z=0.01\end{array}$ & 0.991 \\
\hline Severity of CP & Fisher's exact & 0.953 \\
\hline Caregivers' age & $\begin{array}{l}U=257 \\
Z=-0.15\end{array}$ & 0.878 \\
\hline Caregivers' relationship to child (mother or another relative) & $\begin{array}{l}\chi^{2}=0.00 \alpha \\
d f=1\end{array}$ & 1.0 \\
\hline Caregivers' educational level (no education or further education) & $\begin{array}{l}\chi^{2}=0.347 \alpha \\
d f=1\end{array}$ & $p=0.550$ \\
\hline Caregivers' employment status (employed or unemployed) & $\begin{array}{l}\chi^{2}=3.285 \alpha \\
d f=1\end{array}$ & 0.070 \\
\hline
\end{tabular}

$\alpha$, with Yates correction of continuity.

The only association that approached significance was between clinical stress and unemployment in that there were fewer respondents with clinical stress in the unemployed group $\left(\chi^{2}=3.285\right.$; $d f=1 \cdot p=0.007$.

$\chi^{2}$, chi-square; $d f$, degrees of freedom

fewer respondents with clinical stress in the unemployed group $\left(\chi^{2}=3.285, \alpha, d f=1, p=0.007\right)$ (Table 5).

\section{Psychometric properties of the Caregiver Strain Index (CSI)}

The internal consistency of the Caregiver Strain Index (CSI) was Cronbach's Alpha 0.80 and the only item that resulted in a decrease of Alpha was 'upsetting' as the removal of this item increased Alpha to 0.818. It can be concluded that the CSI yields internally consistent results. As shown in Figure 1 below, the Visual Analogue Scale (VAS) and the CSI were significantly and negatively correlated (Spearman's rho $=-0.33, p=0.027$ ).

The CSI demonstrated concurrent validity; as illustrated in Table 6, the difference in VAS score approached significance 
TABLE 5: Association between caregiver distress and employment status $(N=46)$.

\begin{tabular}{lccccc}
\hline $\begin{array}{l}\text { Type } \\
\text { of stress }\end{array}$ & $\begin{array}{c}\text { Employed } \\
\boldsymbol{n}(\mathbf{\%})\end{array}$ & $\begin{array}{c}\text { Unemployed } \\
\boldsymbol{n} \mathbf{( \% )}\end{array}$ & $\begin{array}{c}\text { Totals } \boldsymbol{n} \\
\mathbf{( \% )}\end{array}$ & Statistic & $p$-value \\
\hline $\begin{array}{l}\text { Minimal } \\
\text { stress }\end{array}$ & $6(33.3)$ & $17(60.7)$ & $23(50)$ & $\begin{array}{c}\text { Chi-Square } \\
=3.285\end{array}$ & 0.070 \\
$\begin{array}{l}\text { Clinical } \\
\text { stress }\end{array}$ & $12(66.7)$ & $11(39.3)$ & $23(50)$ & - & - \\
\hline Totals & $\mathbf{1 8 ( 3 9 . 1 )}$ & $\mathbf{2 8 ( 6 0 . 9 )}$ & $\mathbf{4 6 ( 1 0 0 )}$ & - & - \\
\hline
\end{tabular}

TABLE 6: The association between Visual Analogue Scale (VAS) and the EQ-5D Utility Index Scores of those who were clinically stressed $(N=23)$ and those who were $\operatorname{not}(N=23)$

\begin{tabular}{lccccc}
\hline Score & $\begin{array}{c}\text { Rank sum } \\
\text { clinically stressed }\end{array}$ & $\begin{array}{c}\text { Rank sum } \\
\text { minimal stress }\end{array}$ & $\boldsymbol{U}$ & $\boldsymbol{Z}$ & $\boldsymbol{p}$-value \\
\hline $\begin{array}{l}\text { Index VAS } \\
\text { score }\end{array}$ & 452.0 & 629.0 & 176.0 & -1.93 & 0.053 \\
$\begin{array}{l}\text { Index Utility } \\
\text { Score }\end{array}$ & 463.5 & 617.5 & 187.5 & -1.68 & 0.093 \\
\hline
\end{tabular}

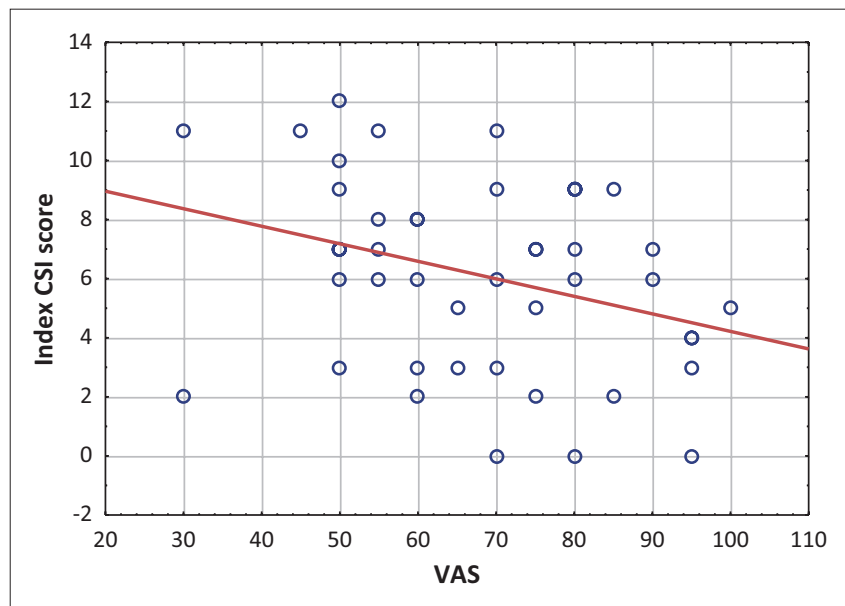

Figure 1: Scatterplot of Care-Giver Strain Index (CSI) and Visual Analogue Scale (VAS) scores.

and the correlation between VAS and CSI score was negative and significant (Spearman's rho $=-0.33, p=0.027$; see Figure 1).

\section{Discussion}

\section{Overview}

It is clear that the caregivers in our study experienced a great deal of stress with half of the respondents reporting clinical stress. This is not surprising given the difficult socioeconomic circumstances of those living in highdensity areas in Harare. However, we did expect to find associations between the CSI and the age of the child, the age of the caregiver and/or the level of severity of the functional limitations and this was not the case. Other unmeasured variables such as the perceived availability of social support or financial resources might be better predictors of caregiver burden. Further, the small sample size could have limited the statistical power of the analyses. Caregivers in Harare reported considerable strain and poor HRQoL most probably due to care-giving and this is similar to findings from other studies which report that caring for a child with CP can be stressful (Murphy et al. 2007; Oh \& Lee 2009; Raina et al. 2004; Sawyer et al. 2011; Tadema et al.
2009). Furthermore, as noted previously (Murphy et al. 2007; Oh \& Lee 2009; Reid, Moss \& Hyman 2005), the burden was multifactorial. Discussion of the results is categorised into physical, economic and psychosocial burden and psychometric properties of the CSI.

\section{Physical burden}

Most of the caregivers reported physical strain on the CSI and pain or discomfort on the EQ-5D. The physical strain or pain may be accounted for by the need for assistance in ADLS due to activity limitations children with CP face (Murphy et al. 2007). Lifting and carrying children might result in pain (Davis et al. 2009). Although not statistically significant, there was a slight increase in the proportion of caregivers reporting of pain thus our findings are suggestive that the intensity of pain may increase with the passage of time. Further, results from a meta-analysis comparing results from the present study and those of the validation of the Shona version of the EQ-5D revealed that, compared to the general population, caregivers of children with CP are more likely to report pain $\left(\chi^{2}=9.968, d f=1\right.$, $p=0.002)$. In addition, in the Zimbabwe situation, there is no adapted transport for the children with disabilities (CWDs) and wheelchairs are not readily available, even for older children. Mothers generally have to carry their children and the traditional method of carrying on the back utilized by the caregivers might give rise to increasing back pain. A weakness of the study was that information on assistive devices was not gathered and these hypotheses need to be tested in further studies.

As our sample consisted of relatively younger caregivers, the prevalence of problems with mobility, self-care and usual activities was low. Further, there were no statistically significant differences in the reported problems over the three-month period. We compared the results from the present and that of the validation of the Shona version of the EQ-5D (Jelsma et al. 2001). Their sample consisted of 42 residents of a high-density suburb in Harare with a mean age of $34.3(\mathrm{SD}=11.3$ ) years. The study setting was the same as our study and the two groups were comparable in terms of age, educational attainment and employment status (Jelsma et al. 2001). Compared to the general population, caregivers of children with $\mathrm{CP}$ are more likely to report mobility problems $\left(\chi^{2}=10.192, d f=1, p=0.001\right)$ and selfcare problems $\left(\chi^{2}=10.889, d f=1, p=0.002\right)$. This indicates that caring for a child with $\mathrm{CP}$ or physical disability may lead to an increased physical burden on primary, informal caregivers.

\section{Economic burden}

Although no comparison was made with the financial situation of parents of typically developing children (which was a weakness of the study), three quarters of respondents reported an increased financial burden. Care-giving leads to compromised working opportunities due to the conflicting demands of care-giving and employment thus 
ultimately resulting in limited opportunities to enter gainful employment (Brehaut et al. 2004; Davis et al. 2009; NavaieWaliser et al. 2002; Raina et al. 2004).

Likewise, in a cross sectional study on 91 Bangladeshi caregivers, a country with similar developmental challenges, and mothers of children with CP between the age of 1.5 and 5 years concluded that care-giving results in an added economic burden. The authors recommended that economic empowerment of caregivers in the form of microcredit programmes may lead to reduced financial burden. They postulated that provision of low cost aids would also help to alleviate physical and financial burden in caregivers (Mobarak et al. 2000). This could also be useful in the Zimbabwean context, particularly in the light of the physical strain discussed above.

As CP is more prevalent in people of lower SES (Ogunlesi et al. 2008), caregivers are likely to have lower educational attainment, have diminished opportunities of finding employment and subsequently are at high risk of financial strain (Mu'ala, Rabati \& Shwani 2008). This is true across different contexts. A Canadian study comparing health outcomes of 468 caregivers of children with $\mathrm{CP}$ with the general population revealed that caregivers had a lower academic attainment, more limited work opportunities and were more likely to be unemployed and subsequently had lower income levels (Brehaut et al. 2004). The mean age of their participants was $40.3(\mathrm{SD}=6.7)$ years and age range was between 23 and 63 years, which was comparable to our sample.

The increase in financial burden with the passage of time can be accounted for by the recurrent usage of medical services (Davis et al. 2009) which adds to the costs of raising a child with a disability. As CP is associated with diverse impairments (Aisen et al. 2011; Becher 2002), children with $\mathrm{CP}$ often require routine medical attention (Davis et al. 2009) and this may overburden limited financial budgets, particularly in those who are drawn from lower SES groups.

Surprisingly, however, our findings suggest that unemployed caregivers were less likely to have clinical stress. This seems to contradict findings from literature, which stipulates that unemployed caregivers are likely to report financial burden and this may contribute towards distress or depression (Mu'ala et al. 2008; Ogunlesi et al. 2008). It may be that caregivers who are employed have difficulty in juggling work and home responsibilities, particularly with the lack of care facilities in the high-density areas. On the other hand, caregivers may have more contact time with their children and this may lead to increase in the bonding between caregiver and child, subsequently leading to care-giving being regarded more as a blessing as opposed to being a burden. This is speculation and more studies utilizing qualitative methodologies are needed to explore this hypothesis.

\section{Psychosocial burden}

Long-term care-giving has been shown to predispose caregivers to strain, stress, anxiety, depression and distress, which is of chronic duration relative to the rest of the population (Brehaut et al. 2004, 2009; Cheshire, Barlow \& Powell 2010; Davis et al. 2009; Navaie-Waliser et al. 2002; Sawyer et al. 2011). Our findings corroborate the sentiments as most caregivers complained of psychosocial problems as measured by the CSI and reported anxiety or depression on the EQ-5D. For instance, over 78\% of caregivers reported at least some problems with anxiety or depression whereas only $50 \%$ of participants in Jelsma et al.'s (2001) validation of the Shona version of the EQ-5D study did so. Further, participants in the present study were more likely to report anxiety and/or depression $\left(\chi^{2}=15.171, d f=1, p<0.001\right)$ compared to the general population. It therefore seems reasonable to attribute the increased anxiety or depression to be secondary to the burden of care giving.

An Irish study on 161 caregivers of children with CP revealed that, female caregivers exhibited lower HRQoL scores as measured by the SF-36 and more so in the mental health component (Parkes et al. 2009). However, the magnitude of anxiety or depression resulting from caring for a child with $\mathrm{CP}$ is difficult to quantify because of methodological flaws in designs of the studies, which have explored the matter. For instance, Cheshire et al. (2010) compared the HRQoL of caregivers of children with $\mathrm{CP}$ and other comorbid conditions ( $46 \%$ of the sample) and came to the conclusion that caring for a child with CP leads to anxiety or depression, yet the comorbid conditions can be confounding to caregiver's HRQoL.

Our results support the literature, which states that caregivers occasionally experience sleep problems (Byrne et al. 2010; Murphy et al. 2007). Children with CP suffer from a wide range of impairments and these may account for abnormal sleep patterns; for instance, pain is prevalent in children with CP and this can lead to the child displaying altered sleep patterns (Hadden \& Von Baeyer 2002; Murphy et al. 2007) which would affect the care-giver, particularly in small homes in which the majority of residents of the two suburbs live. Furthermore, most of the children suffer from communication problems; therefore, 'excessive crying' may be the only viable way of communication and may result in altered sleep for caregivers (Hadden \& Von Baeyer 2002). The altered sleep problems may also be an expression of behavioural problems in the children with CP (Ketelaar et al. 2008). The problem of disrupted sleep needs to be addressed as it may result in further stress in caregivers and physical fatigue, which perpetuates a vicious cycle. This underscores the need to screen and treat pain in children with $\mathrm{CP}$ (Hadden \&Von Baeyer 2002).

Care giving can also result in changes in personal plans and this could influence the social life of caregivers as well as their social connections (Sawyer et al. 2011; Sipal et al. 2010; Skok, Harvey \& Reddihough 2006). As many of the participants 
reported changes in personal plans and that care giving is confining and inconvenient, it is reasonable to infer that caring for a child with CP alters social life and connections as most of the time is spend fulfilling the care giving role.

Care giving can be emotionally draining for caregivers (Cheshire et al. 2010; Makizako et al. 2009; Murphy et al. 2007; Parkes et al. 2009) with behavioural problems being the strongest predictor of maternal stress (Ketelaar et al. 2008; Mobarak et al. 2000; Parkes et al. 2009; Sipal et al. 2010). Caregivers are more likely to suffer from emotional and cognitive problems, as well as chronic illnesses (Brehaut et al. 2004). In our context, emotional problems can stem from the stigmatisation and discrimination related to disability (Myezwa \& M'kumbuzi 2003). Cultural beliefs as to the cause of the disability may contribute towards this stigmatisation and consequently social isolation and emotional problems in caregivers (Hamzat \& Mordi 2007; Myezwa \& M'kumbuzi 2003). CP can be viewed as a curse from ancestral spirits for wrongdoings such as promiscuity during pregnancy (Hamzat \& Mordi 2007). Further, stigmatisation in its worst form, may lead to the locking up of children with CP in homes thus denying them access to medical treatment (Hamzat \& Mordi 2007; Myezwa \& M'kumbuzi 2003).

As reported in literature, caring for a child with $\mathrm{CP}$ can be overwhelming as it can negatively affect caregivers physically, emotionally and psychosocially (Murphy et al. 2007; Oh \& Lee 2009; Palamaro Munsell et al. 2012; Reid et al. 2005). The increase in the proportion of caregivers who felt overwhelmed can be accounted for by the fact that caregiving demands increase with time. Furthermore, the burden is cumulative and chronicity of care has been shown to lead to further deterioration of caregivers' HRQoL.

\section{Psychometric properties of the Caregiver Strain Index (CSI)}

We assessed the internal consistency, test-retest reliability and the concurrent validity of the CSI. The CSI demonstrated good overall internal consistency (Cronbach's Alpha $=0.8$ ), the EQ-5D Visual Analogue Scale of health status and the CSI were significantly and negatively correlated (Spearman's rho $=-0.33, p=0.027$ ), thus demonstrating concurrent validity. In addition, the scores on the CSI remained stable over three months for each item and overall $(Z=0.87$, $p=0.381$ ). Therefore, the CSI and EQ-5D may be used to routinely screen for perceived burden of care and HRQoL of caregivers of children with $\mathrm{CP}$.

\section{Limitations of the study}

As this was a descriptive and analytical longitudinal study and we applied convenience sampling, confounders to burden of care and HRQoL of caregivers cannot be accounted for. In future, comparison of the HRQoL and burden of care of caregivers of typically developing children, evaluation of the number and age of additional children, apart from the child with $\mathrm{CP}$, in the care-givers' care and an assessment of care-givers perceived social support will give a clearer picture of the impact of caring for a child with $\mathrm{CP}$.

\section{Recommendations}

The following recommendations have been made:

- There is a need for routine HRQoL and perceived burden of care assessment in caregivers.

- There is a need for provision of interventions, including the provision of assistive devices, such as wheelchairs to caregivers of children with CP.

- There is a need for the government to provide financial assistance to caregivers of children with $\mathrm{CP}$.

- There is also a need for identification and implementation of models of care, which improve the HRQoL of caregivers in addition to provision of care to children with CP.

\section{Conclusion}

Findings from our study revealed that caregivers of children with $\mathrm{CP}$ in Harare, Zimbabwe, exhibited poor HRQoL with half of the participating caregivers experiencing high levels of stress. Most of the caregivers complained of pain or discomfort, anxiety or depression, economic burden and being overwhelmed by the care-giving role. There is need for surveillance of clinical distress in caregivers of children with CP. Therefore, it is essential to provide these caregivers with continual support through interventions, which may help to improve HRQoL and assist caregivers to deal with the different stressors attendant on caring for a child with $\mathrm{CP}$.

\section{Acknowledgements}

The authors are grateful to the University of Zimbabwe for the funding, which allowed the study to take place. Appreciation is expressed to the caregivers and children with $\mathrm{CP}$ who participated in this study. We applaud your commitment and cooperation throughout the duration of this study.

\section{Competing interests}

The authors declare that they have no financial or personal relationship(s) that may have inappropriately influenced them in writing this article.

\section{Authors' contributions}

Both J.M.D. (University of Zimbabwe) and J.J. (University of Cape Town) contributed to the conceptualisation of the study, the analysis and writing of the article. T.M. (University of Zimbabwe) was involved in the writing of the article. J.M.D. was responsible for the data collection.

\section{References}

Aisen, M.L., Kerkovich, D., Mast, J., Mulroy, S., Wren, T. Al, Kay, R.M. et al., 2011 'Cerebral Palsy: Clinical care and neurological rehabilitation', The Lancet Neurology 10, 844-852. http://dx.doi.org/10.1016/S1474-4422(11)70176-4

Bakas, T., McLennon, S.M., Carpenter, J.S., Buelow, J.M., Otte, J.L., Hanna, K.M. et al., 2012, 'Systematic review of health-related quality of life models', Health and Quality of Life Outcomes 10, 134. http://dx.doi.org/10.1186/1477-7525-10-134 
Becher, J.G., 2002, 'Pediatric rehabilitation in children with Cerebral Palsy: General management, classification of motor disorders', Journal of Prosthetics \& Orthotics 14, 143-149. http://dx.doi.org/10.1097/00008526-200212000-00004

Berker, A.N. \& Yalçin, M.S., 2008, 'Cerebral Palsy: Orthopedic aspects and rehabilitation', Pediatric Clinics North America 55, 1209-1225. http://dx.doi. org/10.1016/j.pcl.2008.07.011

Brehaut, J.C., Kohen, D.E., Garner, R.E., Miller, A.R., Lach, L.M., Klassen, A.F. et al., 2009, 'Health among caregivers of children with health problems: Findings from a Canadian population-based study', American Journal of Public Health 99 a Canadian

Brehaut, J.C., Kohen, D.E., Raina, P., Walter, S.D., Russell, D.J., Swinton, M. et al., 2004, 'The health of primary caregivers of children with Cerebral Palsy: How does it compare with that of other Canadian caregivers?', Paediatrics 114, e182-191. compare with that of other Canadian caregiver

Bugge, C., Alexander, H. \& Hagen, S., 1999, 'Stroke patients' informal caregivers', Stroke 30, 1517-1523. http://dx.doi.org/10.1161/01.STR.30.8.1517

Byrne, M.B., Hurley, D.A., Daly, L. \& Cunningham, C.G., 2010, 'Health status of caregivers of children with Cerebral Palsy', Child: Care, Health and Development 36, 696-703. http://dx.doi.org/10.1111/j.1365-2214.2009.01047.x

Centre, T.S., 2010, 'Submission to the productivity commission inquiry: Disability care and support the economic and social impact of Cerebral Palsy', viewed 12 December 2011, from http://www.pc.gov.au/_data/assets/pdf_file/0005/ 102758/sub0527.pdf

Chen, M.-L. \& Hu, L.-C., 2002, 'The generalizability of caregiver strain index in family caregivers of cancer patients', International Journal of Nursing Studies 39, 823-829. http://dx.doi.org/10.1016/S0020-7489(02)00021-4

Cheshire, A., Barlow, J.H. \& Powell, L.A., 2010, 'The psychosocial well-being of parents of children with Cerebral Palsy: A comparison study', Disability and Rehabilitation 32, 1673-1677. http://dx.doi.org/10.3109/09638281003649920

Cheung, K., Oemar, M., Oppe, M. \& Rabin, R., 2011, 'EQ-5D: User guide - Basic information on how to use EQ-5D', Clinical Infectious Diseases 53, Suppl. 3.

Cieza, A. \& Stucki, G., 2005, 'Content comparison of health-related quality of life (HRQOL) instruments based on the international classification of functioning, disability and health (ICF )', Quality of Life Research 14, 1225-1237. http://dx.doi. org/10.1007/s11136-004-4773-0

Davis, E.S., Waters, B.R., Cook, K. \& Davern, M., 2009, 'The impact of caring for a child with Cerebral Palsy: Quality of life for mothers and fathers', Childcare Healt Development 36, 63-73. http://dx.doi.org/10.1111/j.1365-2214.2009.00989.x

Debuse, D. \& Brace, H., 2011, 'Outcome measures of activity for children with Cerebral Palsy: A systematic review', Pediatric Physical Therapy 23, 221-231. http://dx.doi. org/10.1097/PEP.0b013e318227bbc6

Deepthi, K. \& Krishnamurthy, R.R., 2011, 'Mental health and quality of life of caregivers of individuals with Cerebral Palsy in a community based rehabilitation programme in rural Karnataka', Disability, CBR \& Inclusive Development 22, 29-38.

Eker, L. \& Tüzün, E.H., 2004, 'An evaluation of quality of life of mothers of children with Cerebral Palsy', Disability and Rehabilitation 26, 1354-1359. http://dx.doi. org/10.1080/09638280400000187

Finkenflugel, H., Maannen, V., Van, Schut, W., Vermeer, A., Jelsma, J. \& Moyo, A., 1996, 'Appreciation of community based rehabilitation by caregivers of children with a disability', Disability and Rehabilitation 18, 255-260. http://dx.doi. org/10.3109/09638289609166310

Gagliardi, C., Maghini, C., Germiniasi, C., Stefanoni, G., Molteni, F., Burt, D.M et al., 2008, 'The effect of frequency of Cerebral Palsy treatment: A matchedpair pilot study', Pediatric Neurology 39, 335-340. http://dx.doi.org/10.1016/j. pediatrneurol.2008.07.021

Gorter, J.W., Rosenbaum, P.L., Hanna, S.E., Palisano, R.J., Bartlett, D.J., Russell, D.J. et al., 2004, 'Limb distribution , motor impairment, and functional classification of Cerebral Palsy', Developmental Medicine \& Child Neurology 46, 461-467. http:// dx.doi.org/10.1111/j.1469-8749.2004.tb00506.x

Hadden, K.L. \& Von Baeyer, C.L., 2002, 'Pain in children with Cerebral Palsy: Common triggers and expressive behaviors', Pain 99, 281-288. http://dx.doi.org/10.1016/ S0304-3959(02)00123-9

Hamzat, T.K. \& Mordi, E.L., 2007, 'Impact of caring for children with Cerebral Palsy on the general health of their caregivers in an African community', International Journal of Rehabilitation Research, viewed 22 December 2011, from http://www. ncbi.nlm.nih.gov/pubmed/17762763

Jelsma, J., Mhundwa, K., De Weerdt, W., De Cock, W. \& Chivaura, V., 2001, 'The Shona version of the EQ-5D', Central Africa Journal of Medicine 47, 8-13. http://dx.doi. org/10.4314/cajm.v47i1.8584

Jones, M.W., Morgan, E., Shelton, J.E. \& Thorogood, C., 2007, 'Cerebral Palsy: Introduction and diagnosis (Part I)', Journal of Pediatric Health Care 21, 146-152. http://dx.doi.org/10.1016/j.pedhc.2006.06.007

Karande, S., Patil, S. \& Kulkarni, M., 2008, 'Impact of an educational program on parental knowledge of Cerebral Palsy', Indian Journal of Pediatrics 75, 901-906. http://dx.doi.org/10.1007/s12098-008-0160-0

Ketelaar, M., Volman, M.J.M., Gorter, J.W. \& Vermeer, A., 2008, 'Child: Stress in parents of children with Cerebral Palsy: What sources of stress are we talking about?', Child: Care, Health \& Development 34, 825-829. http://dx.doi.org/10.1111/ j.1365-2214.2008.00876.x

Khan, F., Pallant, J. \& Brand, C., 2007, 'Caregiver strain and factors associated with caregiver self-efficacy and quality of life in a community cohort with multiple sclerosis', Disability and Rehabilitation 29, 1241-1250. http://dx.doi. org/10.1080/01443610600964141
Makizako, H., Abe, T., Shimada, H., Ohnuma, T., Furuna, T. \& Nakamura, Y., 2009, 'Combined effect of factors associated with burdens on primary caregiver', Geriatrics \& Gerontology International 9, 183-189. http://dx.doi.org/10.1111/ j.1447-0594.2009.00523.x

Martin, B., Murray, G., Peter, R., Alan, L. \& Nigel, P., 2005, 'Proposed definition and classification of Cerebral Palsy', Developmental Medicine and Child Neurology 47 571-576.

Mobarak, R., Khan, N.Z., Munir, S., Zaman, S.S. \& Mcconachie, H., 2000, 'Predictors of stress in mothers of children with Cerebral Palsy in Bangladesh', Journal of Pediatric Psychology 25, 427-433. http://dx.doi.org/10.1093/ jpepsy/25.6.427

Moster, D., Wilcox, A.J., Vollset, S.E., Markestad, T. \& Lie, R.T., 2010, 'Cerebral Palsy among term and post-term births', Journal of the American Medical Association 304, 976-982. http://dx.doi.org/10.1001/jama.2010.1271

Mu'ala, E.A., Rabati, A.A. \& Shwani, S.S., 2008, 'Psychological burden of a child with Cerebral Palsy upon caregivers in Erbil Governorate', Iraqi Postgraduate Medical Journal 7, 129-134. http://dx.doi.org/10.1111/j.1365-2214.2006.00644.x

Murphy, N.A., Christian, B., Caplin, D.A. \& Young, P.C., 2007, 'The health of caregivers for children with disabilities: Caregiver perspectives', Child: Care, Health \& Development 33, 180-187. http://dx.doi.org/10.1111/j.1365-2214.2006.00644.x

Myezwa, H. \& M'kumbuzi, V., 2003, 'Participation in community based rehabilitation programmes in Zimbabwe: Where are we?', Asia Pacific Disability \&Rehabilitation Journal 14, 18-29.

Narekuli, A., Raja, K. \& Kumaran, S., 2011, 'Impact of physical therapy on burden of caregivers of individuals with functional disability', Disability, CBR \& Inclusive Development 22, 108-119. http://dx.doi.org/10.5463/dcid.v22i1.17

Navaie-Waliser, M., Feldman, P.H., Gould, D.A., Levine, C., Kuerbis, A.N. \& Donelan, K., 2002, 'When the caregiver needs care: The plight of vulnerable caregivers', American Journal of Public Health 92, 409-413. http://dx.doi.org/10.2105/ AJPH.92.3.409

Ogunlesi, T., Chb, M.B., Ogundeyi, M., Olowu, A. \& Bs, M.B., 2008, 'Socio-clinical issues in Cerebral Palsy in Sagamu, Nigeria', South African Journal of Child Health issues in Cer.
$2,120-123$.

Oh, H. \& Lee, E.O., 2009, 'Caregiver burden and social support among mothers raising children with developmental disabilities in South Korea', Internationa Journal of Disability, Development \& Education 56, 149-167. http://dx.doi. Journal of Disability, Development
org/10.1080/10349120902868624

O'Shea, T.M., 2008, 'Diagnosis, treatment, and prevention of Cerebral Palsy in nearterm/term infants'. Clinical Obstetrics and Gynecology Journal 51, 816-828. term/term infants', Clinical Obstetrics and Gynecol
http://dx.doi.org/10.1097/GRF.0b013e3181870ba7

Palamaro Munsell, E., Kilmer, R.P., Cook, J.R. \& Reeve, C.L., 2012, 'The effects of caregiver social connections on caregiver, child, and family well-being', American Journal of Orthopsychiatry 82, 137-145. http://dx.doi.org/10.1111/j.19390025.2011.01129.x

Parkes, J., McCullough, N., Madden, A. \& McCahey, E., 2009, 'The health of children with Cerebral Palsy and stress in their parents', Journal of Advanced Nursing 65, 2311-2323. http://dx.doi.org/10.1111/j.1365-2648.2009.05089.x

Post, M.W., Festen, H., Van, I.G., Port, D. \& Visser-Meily, J.M., 2007, 'Reproducibility of the Caregiver Strain Index and the Caregiver Reaction Assessment in partners of stroke patients living in the Dutch community', Clinical Rehabilitation 21, 10501055. http://dx.doi.org/10.1177/0269215507079140

Raina, P., Donnell, M.O., Schwellnus, H., Rosenbaum, P., King, G., Brehaut, J. et al., 2004, 'Caregiving process and caregiver burden: Conceptual models to guide research and practice', Bio-Medical Central Pediatrics 4, 1-13.

Raina, P., O'Donnell, M., Rosenbaum, P., Brehaut, J., Walter, S.D., Russell, D., Swinton, M., Zhu, B. \& Wood, E., 2005, 'The health and well-being of caregivers of children with Cerebral Palsy', Pediatrics 115, e626-636. http://dx.doi.org/10.1542/ peds.2004-1689

Reid, C.E., Moss, S. \& Hyman, G., 2005, 'Caregiver reciprocity: The effect of reciprocity, carer self-esteem and motivation on the experience of caregiver burden', Australian Journal of Psychology 57, 186-196. http://dx.doi. org/10.1080/00049530500141022

Robinson, B., 1983, 'Validation of a Caregiver Strain Index', Journal of Gerontology 38 , 344-348. http://dx.doi.org/10.1093/geronj/38.3.344

Rodrigues dos Santos, M.T.B., Bianccardi, M., Celiberti, P. \& De Oliveira Guaré, R., 2009 'Dental caries in cerebral palsied individuals and their caregivers' quality of life', Child: Care, Health and Development 35, 475-481. http://dx.doi.org/10.1111/ j.1365-2214.2009.00976.x

Sawyer, M.G., Bittman, M., La, A.M., Angela, G., Nina, D.C., Raghavendra, P. et al., 2011, 'Time demands of caring for children with Cerebral Palsy: What are the implications for maternal mental health?', Developmental Medicine \& Child Neurology 53, 338-343. http://dx.doi.org/10.1111/j.14698749.2010.03848.x

Sharan, D., Ajeesh, P.S., Rameshkumar, R. \& Manjula, M., 2012, 'Musculoskeletal disorders in caregivers of children with Cerebral Palsy following a multilevel surgery', Work: A Journal of Prevention, Assessment and Rehabilitation 41(1), 1891-1895.

Sipal, R.F., Schuengel, C., Voorman, J.M., Van Eck, M. \& Becher, J.G., 2010, 'Course of behaviour problems of children with Cerebral Palsy: The role of parental stress' Child: Care, Health and Development 36, 74-84. http://dx.doi.org/10.1111/ j.1365-2214.2009.01004.x

Skok, A., Harvey, D. \& Reddihough, D., 2006, 'Perceived stress, perceived social support, and wellbeing among mothers of school-aged children with Cerebral Palsy', Journal of Interllectual Development \& Disability 31, 53-57. http://dx.doi. org/10.1080/13668250600561929 
Sullivan, B.M.T., 2002, 'Caregiver Strain Index (CSI)', Best Practices in Nursing Care of Older Adults 14, 1-2. http://dx.doi.org/10.3928/0098-913420020801-03

Tadema, A.C., Vlaskamp, C. \& Needs, S., 2009, 'The time and effort in taking care for children with profound intellectual and multiple disabilities: A study on care load and support', British Journal of Learning Disabilities 38, 41-48. http://dx.doi. org/10.1111/j.1468-3156.2009.00561.x
Whalen, K.J. \& Buchholz, S.W., 2009, 'The reliability, validity and feasibility of tools used to screen for caregiver burden: A systematic review', JBI Library of Systematic Reviews, viewed 02 November 2012, from http://onlinelibrary.wiley.com/ doi/10.1111/j.1365-2648.2010.05347.x/abstract

Yilmaz, H., Erkin, G. \& Ezke, A.A., 2013, 'Quality of life in mothers of children with Cerebral Palsy', Neurorehabilitation \& Neural Repair 19, 232-237. http://dx.doi. org/10.1155/2013/914738 